\title{
LO VIVENCIAL Y LO VITAL EN ;FELICIDADES! DE JUAN JOSÉ BECERRA
}

\author{
Laureano Ralón \\ Simon Fraser University School of Communication \\ Burnaby, BC, Canadá \\ ralonlaureano@gmail.com
}

Quisiera evitar que esta breve nota se convierta en un spoiler de ¡Felicidades! (2019), la última novela de Juan José Becerra publicada por Seix Barral, y a la vez poder decir algo singular y universal sobre la misma; algo que exprese no tanto el impacto que tuvo en mí (la maravillosa experiencia de leerla, con todos los fantasmas que agita), sino las consecuencias que se propagan con posterioridad al impacto: es decir, sus efectos, o si se quiere, la manera en que la novela se ejecuta a sí misma y da que pensar. En una entrevista reciente con el diario argentino La Gaceta, Becerra declaró que a la literatura le falta una conexión con la vida ("A la literatura" párr. 1). Sin duda, ¡Felicidades! puede leerse como una tentativa de producir este tipo de conexión: de producir la doble captura que significa el devenir literario de la vida y el devenir vital de la literatura. Pero, ¿qué significa "la vida" para Becerra? No queda del todo claro y es la pregunta que me gustaría abordar en estas líneas desde una perspectiva filosófica.

Es evidente que Becerra no se refiere a la constitución material de la vida, pues en ningún momento habla de biología, química o física en ¡Felicidades! Menos obvio, tal vez, sea el hecho de que tampoco le interesa la experiencia fenomenológica de sujetos finitos, encarnados y situados, o lo que aquí llamaremos la dimensión vivencial de la vida. Por "vivencial" entendemos la aparición de un mundo o de una realidad unificada, con todo el espectáculo de solicitaciones que reclama la atención de la conciencia humana y que insume un desarrollo temporal, no solo en la vigilia, sino también en los sueños, pues lo vivencial solo nos da respiro en instancias de sueño profundo, 
es decir, de sueño sin sueño: momentos en los que no somos nadie, apenas un organismo con sus poderes libidinales más secretos y sus deseos más profundos y dispersos; en este tipo de estados, no parece haber manifestación fenoménica alguna, y por lo tanto, tampoco hay vivencias. Sin embargo, por lo bajo, la vida - con sus flujos y procesos ciegos- continúa su lento e infatigable despliegue motorizado por una indeclinable pulsión de muerte.

La hipótesis general de esta nota es que ¡Felicidades! se ocupa de esta otra dimensión de la vida: no de lo vivencial, sino de lo vital; no de lo personal, sino de lo impersonal, no de lo representacional, sino de lo subrepresentacional que se sitúa entre la cosa en sí y el objeto de la experiencia, para expresarlo kantianamente. Esta dimensión es, parafraseando a Deleuze, el noúmeno más cercano al fenómeno, la sensibilidad pura, o el ser de lo sensible. Se trata de procesos inconscientes, maquínicos y moleculares, inaccesibles desde la experiencia vivida en primera persona, esto es, la experiencia que "pone el mundo a la vista", para utilizar una famosa fórmula de John McDowell. Por el contrario, dichos procesos solo pueden captarse de manera indirecta, a través de los efectos que producen diacrónicamente en otras cosas. Así pues, ¡Felicidades! puede concebirse como un medio refractario en el que no solo encontramos una historia, un relato y una trama, con todos los consabidos elementos de una narrativa literaria; posee además una dimensión especulativa, un entramado de intensidades, flujos y potencias que es lo que nos interesa explorar aquí desde una "racionalización imaginativa". Es que podría decirse que lo vital acontece de manera secreta y silenciosa, involuntaria; camina en puntas de pie a espaldas de toda vivencia y habla en una lengua que es algo así como un tartamudeo foráneo, una lengua que habita en el interior de la lengua materna a través de la cual se articula el mundo de las vivencias (la lengua de la socialización y de las normas, la lengua mediante la cual devenimos sujetos de razón).

El propio Cortázar, como es sabido, le asignó una importancia capital al "otro lado de las cosas". Tomó del romanticismo, del surrealismo y del existencialismo la idea de que la realidad posee un excedente no objetivable, un remanente que no se deja representar pasivamente (Descartes) ni constituir activamente (Kant). De hecho, es en la figura sórdida y elegante de Bataille que esta idea alcanza sus vuelos mayores: erotismo, sacrificio y literatura son, a los ojos de este francés anómalo, las figuras máximas del gasto, excesos de vida inapropiable que discurren por detrás del mundo de la razón y de su implacable maquinaria de sentido. Para Cortázar, como para Bataille, muchas experiencias no llegan a adquirir jamás la forma trascendental o epistémica 
del objeto en general, que para Kant era la condición de posibilidad básica de la experiencia universal, sino que se presentan al observador perspicaz (que suele ser el observador distraído) como meras apariencias, simulacros, y todo tipo de realidades amorfas o 'extra-seres' que desafían los lineamientos del sentido común y el buen sentido. Fue en los intersticios de la realidad, entendida como un espacio lógico-objetivo y perfectamente determinado, que Cortázar buscó para su literatura esos destellos de lo Real (con mayúscula) que subyacen a nuestra experiencia cotidiana, más reales que la realidad misma entendida como una configuración objetivista, materialista y mecanicista. Se trata de una tendencia que se evidencia tempranamente en el cronopio mayor. En una de las cartas más potentes de todo su epistolario, dirigida a su íntimo amigo Fredi Guthmann y escrita en el verano de 1951, un Cortázar que acaba de regresar maravillado de su primer viaje a Europa y se desvelaba pensando en dar un salto definitivo al lado de allá, escribía las siguientes líneas:

Todo lo que he trabajado en este año pasado y lo que va del 51, sobre todo la tarea abrumadora de escribir el libro sobre Keats, me ha mostrado claramente cómo me sostengo precariamente en lo real, cómo las palabras me engañan y me dan una provisoria seguridad, cómo una buena dosis de lecturas me ayuda como si fuera morfina a sobrevivir y a creer -no siempre, por suerte- que tengo lo que la gente llama una "cultura" -eso que en la mayoría de los casos es un buen sistema de defensas, de límites, de nociones- es decir una barricada contra lo que empieza más allá, que es lo Real. Seguro estoy, después de seis meses de trabajar noche a noche sobre los textos keatsianos, sobre mis recuerdos, sobre mis 'iluminaciones', que no tengo de la realidad más que una idea provisoria y lamentable -como la tenía el mismo Keats, que se salvaba por su prodigioso don lírico, que iba más allá de él-. A veces, con lo que pueda yo tener de poeta, entreveo fulgurantemente una instancia de esa Realidad: es como un grito, un relámpago de luz cegadora, una pureza que duele. Pero instantáneamente se cierra el sistema de las compuertas; mis bien educados sentidos se reajustan a la dimensión del lunes o del jueves, mi bien entrenada inteligencia se ovilla como un gato en su cama cartesiana o kantiana. Y el noúmeno vuelve a ser una palabra, una bonita palabra para decirla entre dos pitadas al cigarrillo (312).

Keats y Guthmann fueron los principales interlocutores en este período pre-cortazariano que fue algo así como un despertar metafísico para el cronopio mayor: lleno de angustia, pero también lleno de intuiciones poderosísimas que 
en años posteriores iban a nutrir filosóficamente su literatura de vanguardia. Lo que nos revela este párrafo es que la concepción cortazariana de la mente no era la de un espejo que refleja, sino la de una lámpara que descubre y colorea una realidad que viene de alguna manera provista de una estructura proto-categorial básica y que es más o menos inteligible de suyo; solo hace falta un poco de arte para exorcizarla y mantener abiertas las compuertas por el mayor tiempo posible. Queda claro, por lo tanto, que su modelo de la realidad fue expresivo más que representativo o constitutivo, y que fue a partir de dicha lógica que Cortázar intentó capturar la esencia de la vida a través de las letras. Después de todo, no hay que olvidar que Cortázar fue un amante de la vida y, emulando un gesto de ecos nietzscheanos, concibió su propia vida como una obra de arte.

Sin embargo, sus esfuerzos permanecieron demasiado atados a una imagen manifiesta del pensamiento, es decir, a una suerte de psicología y de física folk basada en esa forma privilegiada de intuición que es la percepción y que, como dicen los fenomenólogos, nos pone en contacto con los objetos en carne y hueso. De hecho, para ser justos, lo que le interesaba a Cortázar no eran los fenómenos propiamente dichos, sino la multiestabilidad de los fenómenos: de ahí su orientación lúdica, su estrecha alianza con las artes, y la idea de que hay que aprender a mirar y conservar por siempre la visión del niño. Dicho abordaje no deja de tener interesantes resonancias con la pop-filosofía de Deleuze, que toma una distancia radical de los hábitos y presupuestos que hacen de la lectura un hábito de comprensión y de la escritura un ejercicio de interpretación. Para Deleuze, como puede serlo para Cortázar, en un libro no hay nada que entender ni nada que comprender; todo es un conjunto de afectos y de efectos que pasan o no pasan; no hay nada más que pueda hacerse con ellos. La ética deleuziana, al igual que la cortazariana, es una suerte de fatalismo estoico.

Becerra, por su parte, va mucho más allá que Cortázar en su exploración de la dimensión "vital" de la vida. Parafraseando a Deleuze, le interesa la vida que confluye en una vida, la vida que, gracias a su carácter anónimo y singular, adquiere un estilo propio. Su abordaje es más especulativo que fenomenológico o existencialista, y su concepción de la mente no es ni la de un espejo (racionalismo) ni la de una lámpara (romanticismo). Por el contrario, en ¡Felicidades! descubrimos que el pensamiento ha sido arrancado por completo del sujeto y diluido en las cosas mismas. Inmanencia del pensar, podríamos llamarle. El resultado es una suerte de pensamiento en genitivo, un pensamiento que parte de las cosas mismas más que de la imposición 
de estructuras formales y a priori por parte de un sujeto cognoscente que, paradójicamente, es pero no es parte del mundo del que forma parte: una suerte de ángel o espíritu encarnado en un cuerpo humano. Un pensamiento en genitivo tiende a lo procesual más que a lo sintético, y un abordaje filosófico que se proponga investigar su estructura programable debe partir de una concepción no psicológica de la mente y de los conceptos que se ocupe ya no de las condiciones formales de la experiencia posible, sino de las condiciones materiales (ontogenéticas) de la experiencia real. Es que por debajo de la experiencia vivida, de lo vivencial, se despliega una pluralidad de procesos impersonales e intensivos que son subrepresentativos e informes, y que moldean la materialidad de lo sensible a través de una multiplicidad de microdecisiones inconscientes, o lo que el filósofo británico Alfred North Whitehead llamó "prehensiones".

En ¡Felicidades!, Becerra explora justamente esta dimensión maquínica y molecular, y su afirmación de que a la literatura le hace falta una conexión con la vida debe entenderse en relación con este plano vital, es decir, no psicológico y no figurativo, de la vida. Deleuze llamaba a esta conexión "conjunción disyunta o devenir", términos que deben entenderse como un movimiento continuo de doble captura en el que los elementos que entran en dicho proceso no establecen una relación de imitación recíproca, sino un proceso de modificación mutua que tiene como producto un movimiento de desterritorialización de los términos en juego: el devenir de la continuidad, más que la continuidad del devenir. Dichas conexiones son rizomáticas, laterales, transversales y menores, para continuar con la jerga deleuziana; son las excepciones, lo extraño, lo raro, lo bizarro que ocurre ya no en los intersticios de la percepción (lo cual supone un ejercicio que sigue siendo antropocéntrico, una suerte de voluntarismo que invita a la cultivación de los sentidos), sino más allá de la imagen manifiesta del pensamiento, en una zona de lo indiscernible en la que las cosas pueden ser esto o aquello, o incluso esto y aquello. Más que los intersticios que se abren a partir de una interacción gestáltica entre figura y fondo, Becerra se ocupa de las irrupciones, de las líneas de fuga, que desequilibran el cara a cara del ser humano con el mundo, irrupciones que expresan todo tipo de cambios de intensidades, además de una tendencia del bajo-fondo estético a subir a la superficie con nuevas formas. ¡Felicidades! trabaja con la aberración de hacer desbordar este bajo-fondo, con los simulacros que se autonomizan de los objetos de la experiencia para adquirir vida propia, amenazando con inundar, "en un movimiento aberrante", para tomar un término clave de David Lapoujade, la 
superficie de la experiencia cotidiana, sujetada por la rutina y el automatismo. Es el barro que se subleva, el barroquismo que subyace al mecanicismo. (Aunque estilísticamente Becerra sea un discípulo de Aira y de Borges, en el plano filosófico y ficcional lo suyo es el barroco).

Estas claves de lectura -el énfasis en lo vital más que en lo vivencial, en la especulación más que en la percepción o la experimentación con las formas, en los procesos preindividuales y anónimos más que en la experiencia vivida-sugieren que lo esencial de ¡Felicidades! no es la trama, que sin duda es maravillosa pero en última instancia no deja de ser una excusa para todo lo otro (una excusa necesaria, claro, pues invierte aquel viejo y cansado apotegma de que el medio es el mensaje). Lo esencial de la novela -lo que hace que funcione y se ejecute y dé que pensar- es lo que ocurre en la dimensión vital, que como el magma y los temblores de un volcán hacen que la narrativa traccione y se desterritorialice en un vértigo de la inmanencia, en un viaje a la deriva donde cualquier cosa puede pasar. Se trata entonces de una literatura que, desde una perspectiva ontológica, sería la puesta en obra de un mundo cuya única ley inviolable es el acontecer de lo contingente, de un mundo que, parafraseando a Nietzsche, se produce cuando la mano de hierro de la necesidad sacude la cornucopia del azar.

La "figura" de Cortázar, como era de esperarse en una novela de corte vitalista, ocupa un lugar fundamental, pero de ninguna modo un lugar central. Si pongo la palabra figura entre comillas es porque Cortázar está pero no está en el relato: pese a la rimbombante portada del libro, no es el protagonista de la historia ni mucho menos; más bien ha sido disuelto en las formas para transformarse en una suerte de trasfondo omnisciente, de pasado inmemorial, de presencia virtual, atomizada y larvaria. Se ha convertido, para continuar con el registro deleuziano, en el "personaje conceptual" que anima el relato todo, algo así como la dimensión trascendental de la novela: un centro gravitacional de organización de representaciones, o para expresarlo en un registro más cortazariano, "las babas del diablo que aglutinan la trama, la telaraña sobre la que se posa la mosca". Es en el sutil tratamiento que Becerra le brinda a Cortázar donde queda claro que ¡Felicidades! es mucho más que una novela. $\mathrm{Y}$ en este sentido no debe sorprender que para Becerra la novela sea el género literario más rico, ya que es capaz de abarcar todos los demás géneros.

Así pues, no debe extrañarnos que jFelicidades! sea -también- un texto de crítica literaria que busca llegar a términos no solo con el legado de Cortázar, sino con la figura platónica del crítico-juez. Aquí la crítica es más un ejercicio de prolongación y de expresión de una obra que el ejercicio 
de su censura o de su asimilación a un canon; se trata de un ejercicio en el que los bordes que separan a la obra de la crítica se desdibujan. Y como tal, ¡Felicidades! forma parte de una nueva ola de los estudios críticos sobre Cortázar, una ola que adquirió un impulso notable a partir de los cincuenta años de la publicación de Rayuela en 2013 y el centenario de Cortázar en 2014, pero que se originó con la aparición de su correspondencia completa, compilada póstumamente por Aurora Bernárdez y Carles Álvarez Garriga y publicada en 2012 por Editorial Alfaguara. Algo importante a tener en cuenta en relación con el epistolario es que, ya desde sus años mozos como docente en pueblos y ciudades de provincia (Bolívar, Chivilcoy, Mendoza), Cortázar parecía concebir su correspondencia como un ejercicio para toda la vida. A mi juicio, las cartas son la autobiografía que jamás escribió y su mejor biografía. En ellas se puede apreciar a un hombre menos perfecto, tal vez, pero sin duda mucho más auténtico que ese producto editorial que se fabricó hacia fines de los años sesenta con la mediación de sus interlocutores cubanos y fogoneado en buena medida por el propio escritor y su compañera del momento, Ugné Karvelis. En pocas palabras, el de la correspondencia es un Cortázar secreto y esencialmente ecléctico que la crítica recientemente ha comenzado a descifrar. En lugar de disociar vida y obra por miedo a incurrir en un biograficismo ingenuo, los estudios cortazarianos pueden encontrar en las cartas una serie de valiosas pistas para resignificar su figura en pleno siglo XXI. Becerra coincide. En entrevista con Infobae declara:

Si yo tuviese que quedarme con algo hoy, me quedo con las cartas. Las cartas son extraordinarias. Y lo que más me impresiona es que son muy parecidas a las cartas de Lamborghini porque desde muy jóvenes los dos hablaban como escritores consagrados, o sea, como si hubiesen intuido el futuro en el cual iban a ser grandes figuras literarias, cada cual a su modo, ¿no? (párr. 47).

Dicho sea de paso, no cabe duda de que Becerra - cuyo estilo de escritura "a la deriva" le debe muchísimo a César Aira- ha logrado llegar a términos con el legado de Cortázar de una manera mucho más armónica que el propio Aira, cuya relación con Cortázar es mucho más conflictiva y compleja. En entrevista con la revista Culto, Becerra declaró:

A mí, en todo caso, me llama un poco la atención la lapidación de Cortázar, porque me parece que Aira tiene un pie en cada matriz: en 
la borgeana, que es la de la especulación, y el otro pie en una especie de cuna surrealista, que es la que deriva también de Cortázar. Es decir que hay algún tipo de hermandad, por lo menos al principio, con al principio me refiero al Aira lector, de la que se desatiende por vergüenza, pero no sé si la vergüenza es un valor para la literatura. No quiero cuestionar la genialidad de Aira como escritor, pero me parece que hay un drama ahí, cuyas cosas no alcanzo a ver del todo (párr. 7).

Nótese que tanto Becerra como Aira han reconocido que fue Cortázar quien por primera vez les hizo desear querer ser escritores. Sin embargo, Becerra logra algo como crítico que el propio Aira, pese a su inmenso talento, no alcanza, quedándose apenas en la mera oposición o negación. Es que en ¡Felicidades! Becerra se ha propuesto realizar desde la novela lo que los comentaristas literarios vienen realizando desde la crítica propiamente dicha: una lectura a contrapelo del Cortázar mítico.

Con Deleuze, entiendo por "mito" una "ortodoxia interpretativa" que, de manera más o menos directa y explícita, ejerce una notable influencia sobre buena parte de los estudios críticos en torno a la vida y obra del escritor argentino. En términos filosóficos, se trata de un centro gravitacional de identidad que, en conjunción con un principio trascendental de distribución de diferencias, organiza jerárquicamente el universo cortazariano conforme a una lógica de modelo y copia. Dicho centro cumple la función de seleccionar aquellos "pretendientes" (o representaciones) que mejor se ajustan a una cierta imagen del escritor, celosamente resguardada por la industria editorial, sus herederos y un corpus crítico cuya finalidad es preservar intacto el legado de Cortázar, desalentando toda lectura crítica que no se consustancie con la noción de "el hombre nuevo". Este concepto ordenador, con el que se ha buscado estabilizar la figura de Cortázar desde fines de los años sesenta, se funda en la idea romántica de un individuo absolutamente coherente consigo mismo y con los demás; que piensa lo que dice y dice lo que piensa; que desde niño fue construyendo su vida como si fuese una obra de arte, entregándose por completo a una vocación literaria heredada de su madre y moldeada por una profunda autoexigencia. Este ideal aséptico y ascético - que naturalmente se alimenta de muchos elementos de verdad, aunque sobredimensionadosnos presenta a un Cortázar para los tiempos: una suerte de superhombre con múltiples aristas, aunque en última instancia reductible a dos facetas opuestas pero complementarias. 
Como escritor, Cortázar fue una suerte de "faro" para las nuevas generaciones, protagonista en primera persona del "boom" latinoamericano y uno de los principales exponentes de la renovación literaria en nuestro continente. Como individuo, fue sumamente carismático y generosísimo con su tiempo; celebró desinteresadamente la amistad y estuvo profundamente enamorado de la vida - a punto tal de morir de pura tristeza tras el fallecimiento prematuro de su compañera, Carol Dunlop-. Como intelectual, participó activamente del Mayo francés y tuvo una relación incondicional con el socialismo utópico latinoamericano (Cuba primero, Nicaragua después). Durante la década del setenta, mientras las dictaduras militares se extendían por todo el cono sur, Cortázar se entregó de lleno a la militancia, dedicándole una gran cantidad de tiempo a la redacción de solicitadas, a las mesas redondas, y otras tantas actividades relacionadas con su involucramiento en el Tribunal Russell. La lista no termina allí, pero es más que suficiente para comprender la clase de hombre que tenemos en frente. Se trata de una figura que pide a gritos ser desterritorializada.

Sobre este trasfondo, veamos cómo ¡Felicidades! articula entre líneas su propia lectura crítica focalizándonos en ese personaje conceptual que es el Cortázar de Becerra. Como ya hemos señalado, Cortázar está pero no está presente en la novela, pues se ha visto reducido a una especie de éter elemental, de trasfondo omnisciente, de penumbra de posibilidades en la que se instala el relato para poder hacer lo suyo. Es que Cortázar está completamente disuelto en iFelicidades!, convertido en una especie de sustrato del que se nutren (o mejor dicho, mal nutren) los personajes de la novela -el glifosato que fertiliza una serie de actos decadentes por parte un hombre en plena crisis de la mediana edad. Más que centro organizador, la función que cumple Cortázar en la obra es un entramado omnipresente que se distribuye por todo el cuerpo textual (tal como se distribuía por todos los rincones del cuerpo el alma de los primeros atomistas). Dicha función tal vez pueda esclarecerse en conexión con una serie de declaraciones que hace Deleuze sobre Minelli en relación con la importancia de la creación de conceptos para el constructivismo filosófico:

Me parece que el sueño concierne, antes que nada, a los que no sueñan. El sueño de los que sueñan les concierne a los que no sueñan... y ¿por qué? Porque desde que existe el sueño del otro, existe peligro. A saber, el sueño de la gente es siempre un sueño devorante que nos hace peligrar de ser tragados. Y que los otros sueñen es muy 
peligroso porque el sueño es una terrible voluntad de poder y cada uno de nosotros es más o menos víctima del sueño de los otros, aun cuando sueña la más graciosa joven, aun cuando es una joven muy grácil, es una terrible devoradora, no a causa de su alma, sino por sus sueños. Desconfíen del sueño de los otros, porque si son tomados en sus sueños, están perdidos (¿Qué es el acto de creación? s/p).

Algo parecido -aunque diferente- puede decirse del modo en que Cortázar, convertido en una especie de bajo-fondo estético por Becerra, sostiene la trama de ;Felicidades! como una suerte de fluido universal. Y hasta podría decirse que la miseria de los personajes, al menos en la primera parte de la novela (¿el lado de allá?), pasa por estar atrapados en una suerte de inconsciente cortazariano, de inmensa memoria, algo parecido (pero nunca igual) a lo que sucede de forma más literal y figurativa en "La memoria de Shakespeare" de Borges. La diferencia es que, en iFelicidades!, los personajes se encuentran contaminados por los sueños de un "cierto" Cortázar, a saber, un Cortázar consumado del que todos de alguna manera sabemos algo. La medianía de este Cortázar pronto se vuelve opresiva: desde el principio de la novela el protagonista, a quien se le ha encomendado organizar una muestra en honor del gran cronopio en el Museo de Bellas Artes, lucha por mantener una distancia crítica y cínica respecto del escritor para evitar la proliferación de los consabidos clichés, tendientes a reproducir el Cortázar mítico. Becerra es muy consciente del peligro que representa la organización mítica del legado de un escritor. En el caso de Cortázar, una cierta imagen del pensamiento lo ha reducido al lugar de escritor de iniciación para adolescentes, pero esta caricatura no es el mismo autor que Becerra y Aira leyeron en su juventud; han pasado varias décadas y el mito se ha naturalizado en su lugar, reflejando más y más de lo mismo. A través de su protagonista, Becerra lucha por llegar a términos con la figura de Cortázar, por encontrar algo genuino por fuera de las coordenadas del espacio mítico. El distanciamiento crítico, escéptico y cínico del protagonista, así como el estilo de escritura a la deriva de Becerra, el cual se intensifica en la segunda mitad del libro, apuntan a la diferencia más que a la identidad o identificación. Hay en estos elementos un reconocimiento tácito de que el fenómeno cortazariano, más que fenómeno, es un proceso que alude a una multiplicidad. Por lo tanto, lo más rescatable de Cortázar no es el producto acabado, la punta del iceberg, el fenómeno social, sino su devenir - un devenir que, como si se tratara de una boda entre dos reinos, no supone un cierre identitario ni la tensión inacabable de un 
dualismo en perpetuo contraste (Cortázar con barba, Cortázar sin barba; Cortázar intelectual comprometido con todas las revoluciones de América latina, Cortázar burguesito ciego ajeno a todo lo que trascurre más allá de la esfera estética). El protagonista de la novela logra imponer este concepto ante la mediocridad de otras propuestas que se mueven ya siempre en el plano de las formas, de un Cortázar consumado, agotado por el mito. La idea del protagonista de exaltar el devenir (más que el "ser") cortazariano, destacando la importancia de un texto literariamente menor, pero filosóficamente muy rico, como "Las Puertas del Cielo," finalmente se impone, y es a partir de esta decisión que la novela se pone en marcha y avanza hacia una implacable desterritorialización del mito.

Becerra acierta con este concepto, como también acierta cuando juzga que la correspondencia cortazariana es hoy por hoy el segmento discursivo más importante de toda su producción literaria. Podríamos decir que las cartas de Cortázar son confesiones sin interlocutor posible, ya que en ellas uno se encuentra con otro Cortázar, un Cortázar “otro", menos planchadito y liso, si se quiere, donde predominan los pliegues, lo estriado. En ellas se consuma eso que Deleuze llama, con tanto celo, el estilo y que, al igual que la vida, es un movimiento de desterritorialización que no consiste en una construcción o una biografía, sino en un modo de agenciamiento en el que lo único que se logra es el uso peculiar de la propia lengua, un devenir otro al interior de sí mismo. Y como no podría ser de otro modo, la idea de un devenir cortazariano Becerra la va a canalizar extrayendo un doble, o para expresarlo en términos hegelianos más que deleuzianos, a través de una negación determinada, que siempre es más que la mera oposición o negación abstracta que define el tipo de relación conflictiva que alguien como Aira mantiene con Cortázar. Por el contrario, Becerra busca llegar a términos con Cortázar explorando su otro lado; pero no se trata del otro lado de las formas, con su multiestabilidad fenoménica, pues el devenir otro (la extracción de un doble) es una operación mucho más sutil. Como señala Deleuze, se trata de un devenir sin algo devenido, de una metamorfosis que no es un mero juego de formas, de la constitución de un estilo y de un encanto: el primero, fuente de escritura; el segundo, fuente de vida.

Para canalizar este devenir, Becerra opta por rescatar a un escritor salido del propio riñón de Cortázar más que por jugar con posibilidades inherentes al propio Cortázar: un escritor cuyo destino no es el de los cafés ni las galerías de París o Buenos Aires, sino el de las frías calles de Nueva York. Sin duda el aspecto más intenso, contestatario y desterritorializante de la novela es la 
introducción de la figura del escritor linyera, una personificación de Néstor Sánchez. Aquí las resonancias con Cortázar son particularmente fuertes: en las últimas escenas de Rayuela, como se recordará, encontramos a un Oliveira ya en decadencia en París, y la cuestión de la vida linyera aparece fugazmente. Sin embargo, Oliveira es rápidamente deportado a Buenos Aires y la novela pasa rápidamente al "lado de acá," donde la narrativa es reabsorbida estéticamente por los distintos rituales porteños; en otras palabras, Cortázar no se detiene a explorar esa zona salvaje de lo indiscernible que sí va a explorar frenéticamente Becerra. Es como si entre el lado de allá de Europa y el lado de acá de Buenos Aires, Becerra abriera un paréntesis en Nueva York, donde los movimientos maquínicos y de supervivencia de la dimensión vital se intensificaran e hicieran que lo informe subiese con más fuerza a la superficie. Parafraseando una vez más a Deleuze, "Nueva York es el desierto y Néstor Sánchez el nómada que lo atraviesa". Sin embargo, en última instancia, lo que le interesa a Becerra es el salto, el devenir linyera, más que el ser linyera -como también a Deleuze le interesaban los cambios de identidad, ¿qué hace que Fitzgerald deje de escribir y se vuelva un alcohólico depresivo irrecuperable?

Para cerrar esta breve reseña, diré simplemente que ¡Felicidades! muestra desde la propia literatura lo que críticos literarios como Diego Tomasi, Jaime Correas, Carolina Orloff y Miguel Dalmau vienen tratando de mostrar desde hace tiempo por la vía ensayística: que hay otro Cortázar, o mejor dicho, otros Cortázar, un Cortázar otro. Becerra, a través de su protagonista, nos invita a sumergirnos en ese bajo-fondo estético, procesual y vital a través de las experiencias límites del escritor linyera, salido del propio riñón cortazariano: la extracción de un doble -una diferencia pura o diferencia en sí- que es mucho más que la mera posibilidad de un concepto.

\section{BIBLIOGRAFÍA}

Becerra, Juan José. ¡Felicidades! Buenos Aires, Seix Barral, 2019.

“A la literatura le falta una conexión con la vida". La Gaceta (web), 29 de septiembre de 2019, consultado el 21 de noviembre de 2021, disponible en: https://www.lagaceta. com.ar/nota/819715/la-gaceta-literaria/a-literatura-le-falta-conexion-vida.html

“Juan José Becerra, autor de ‘¡Felicidades!’: En la literatura argentina hay una relación modesta con el cuerpo". Infobae (web), entrevista con Hinde Pomeraniec, 19 de junio de 2019, consultado el 21 de noviembre de 2021, disponible en: https://www.infobae.com/ 
cultura/2019/06/19/juan-jose-becerra-autor-de-felicidades-en-la-literatura-argentina-hayuna-relacion-modesta-con-el-cuerpo/

"Juan José Becerra: Va a quedar una sola actividad cultural en los próximos siglos

que va a ser el turismo cultural". Revista Culto (web), entrevista con Gonzalo León, 30 de agosto de 2019, consultado el 21 de noviembre de 2021, disponible en: https://culto. latercera.com/2019/08/30/juan-jose-becerra-cortazar-entrevista/

Cortázar, Julio. Cartas, Vol. 1 (1937-1954). Aurora Bernárdez y Carles Álvarez Garriga (eds.), Barcelona, Alfaguara, 2012.

Dalmau, Miguel. Julio Cortázar: El Cronopio Fugitivo. Barcelona, Edhasa, 2015.

Deleuze, Gilles. “¿Qué es el acto de creación?” Conferencia en la Femis: Escuela Superior de Oficios de Imagen y Sonido, 1987. YouTube (web), consultado el 21 de noviembre de 2021, disponible en: https://www.youtube.com/watch?v=dXOzcexu7Ks

Lapoujade, David. Deleuze: Los movimientos aberrantes. Buenos Aires, Editorial Cactus, 2016.

McDowell, John. Having the World in View: Essays on Kant, Hegel, and Sellars. Cambridge, Harvard University Press, 2009.

Orloff, Carolina. La Construcción de lo Político en Julio Cortázar. Buenos Aires, Godot, 2015.

Ralón, Laureano. “Julio Cortázar y César Aira: Conexiones Rizomáticas.” Modern Language Notes (Hispanic Issue) 134, º2, 2019, pp. 382-411.

Tomasi, Diego. Cortázar por Buenos Aires, Buenos Aires por Cortázar. Barcelona, Seix Barral, 2013. 